\title{
A Study of Electron Paramagnetic Resonance on Copper Ions on Alkali-Alkali Earth Zinc Phosphate Glass
}

\author{
H. M. Mokhtar ${ }^{1,}$, S. Saad ${ }^{2}$, A. Abd El-ghany ${ }^{1}$, N. H. Mousa ${ }^{1}$, M. M. Elokr ${ }^{3}$ \\ ${ }^{1}$ Physics Department, Faculty of Science, Girls, Al-Azhar University,Cairo, Egypt \\ ${ }^{2}$ Physics Department, Faculty of Science, Modern Academy,Cairo, Egypt \\ ${ }^{3}$ Physics Department, Faculty of Science, Al-Azhar University, Cairo, Egypt \\ Email address: \\ hananlsd38@yahoo.com (H. M. Mokhtar)
}

\section{To cite this article:}

H. M. Mokhtar, S. Saad, A. Abd El-ghany, N. H. Mousa, M. M. Elokr. A Study of Electron Paramagnetic Resonance on Copper Ions on Alkali-Alkali Earth Zinc Phosphate Glass. American Journal of Physics and Applications. Vol. 3, No. 3, 2015, pp. 92-96.

doi: 10.11648/j.ajpa.20150303.15

\begin{abstract}
P}_{2} \mathrm{O}_{5^{-}}-40 \% \mathrm{ZnO}-2 \% \mathrm{CaO}-(16-\mathrm{x}) \% \mathrm{Na}_{2} \mathrm{O}-\mathrm{xCu}_{2} \mathrm{O}$ glass system $(\mathrm{x}=\mathrm{o}, 2,4,6,8,10 \%$ mol $)$ were prepared by conventional melt-quenching technique. It was investigated by means of electron paramagnetic resonance (EPR) to study the structural changes induced by different amount of copper ions. The spin Hamiltonian parameters like $\mathrm{g}_{\|}, \mathrm{g}_{\perp}$ and $\mathrm{A}_{\|}$show that $\mathrm{Cu}^{+2}$ ionare in tetrahedral coordination with $\mathrm{d}_{\mathrm{xy}}$ as the ground state. Modification of EPR band width by increasing copper content suggests that band consists of two overlapping bands; one of them is related to asymmetric band due to isolated copper ions and the other is symmetric due to cluster ions $\mathrm{Cu}^{+2}-\mathrm{Cu}^{+2}$. Calculation of the optical basicity indicates to that polarizability decrease by increasing copper content due to increase electron cloud density at the $\mathrm{Cu}^{2+}$ site.
\end{abstract}

Keywords: Glass, Electron Paramagnetic Resonance, Optical Basicity, Polarizability, Cluster Ions

\section{Introduction}

It is well known that phosphate glasses containing transition metals (TM) have marvelous properties over than silicate or borate glass. This is because their low glass transition temperature $\left(\mathrm{T}_{\mathrm{g}}\right)$, high refractive index, low melting temperature and have the ability to accommodate high concentration of transition metal ion and remain amorphous [1-4]. However, it has a low chemical durability; the addition of transition metal such as zinc oxide enhances its chemical durability, optical properties and decreases the melting temperature. Also adding of alkali or alkali-earth plays an important role in enhancing electrical and magnetic properties, decreasing the melting temperature and a bubble free [2,3].There are special attention on copper doped phosphate glass due to their wide range applications like solid state lasers, optical filter and super ionic conductors [5, 6]. In general, copper behaves as modifier, but in some situation acts as a former in glass network. Copper can exist as a metallic copper $\mathrm{Cu}^{0}$, cuprous $\mathrm{Cu}^{+1}$, and cupric $\mathrm{Cu}^{+2}[7-$ 15]. The electronic structure of copper is $3 \mathrm{~d}^{10} 4 \mathrm{~s}^{1}$; cuprous $\mathrm{Cu}^{+1}$ ion has a completed $\mathrm{d}$ shell. Cuprous $\mathrm{Cu}^{+1}$ does not have a magnetic moment and does not produce a color [8-15].
While $\mathrm{Cu}^{+2}$ have a free spin which is responsible a color according to ligand field theory. EPR technique is used to investigate the valence states and local symmetry (octahedral or tetrahedral). Addition of copper to phosphate glass exhibit anomalous spin parameters A and g [3, 16-19].

Usually incorporation copper into phosphate glass acts as modifier. However, in special cases it can act as a glass former $[17,18]$. The aim of the work is studying the mode of distribution around cupric ionsusing EPR spectra for determination of paramagnetic magnetic susceptibility and some parameters such as Fermi-contact and optical basicity.

\section{Experimental Work}

Copper-doped glasses of varying basic hosts including zinc sodium calcium phosphate (Table1) were prepared by conventional melt-quenching technique. Starting reagent ingredients $\mathrm{Na}_{2} \mathrm{CO}_{3}, \mathrm{ZnO}, \mathrm{CaO},\left(\mathrm{NH}_{4}\right) \mathrm{H}_{2} \mathrm{PO}_{4}$ and $\mathrm{Cu}_{2} \mathrm{O}$ were used for preparation. Appropriate quantities of ingredients are weighed using electric single pan balance of $10^{-3} \mathrm{~g}$ sensitivity. The ingredients were then thoroughly mixed by agate mortar. Each composition was taken in an open porcelain crucible and calcined at $340{ }^{\circ} \mathrm{C}$ for 1 hour to release undesired gases; the furnace was then raised to $950^{\circ} \mathrm{C}$ for 
2hour. The prepared samples were immediately transferred into preheated stainless steel molds for annealing adjusted at $340^{\circ} \mathrm{C}$ for 4 hour. The compositions of the prepared sample are listed in table (1).

Table (1). Chemical composition of the prepared glass.

\begin{tabular}{|c|c|c|c|c|c|}
\hline $\mathrm{Cu}_{2} \mathrm{O}$ addedMol (\%) & $\mathrm{Na}_{2} \mathrm{O} \mathrm{Mol}(\%)$ & CaOMol (\%) & ZnOMol (\%) & $2\left\{\left(\mathrm{NH}_{4}\right) \mathrm{H}_{2} \mathrm{PO}_{4}\right\} \mathrm{Mol}(\%)$ & Sample name \\
\hline 0 & 16 & 2 & 40 & 42 & $\mathrm{~S}_{1}$ \\
\hline 2 & 14 & 2 & 40 & 42 & $\mathrm{~S}_{2}$ \\
\hline 4 & 12 & 2 & 40 & 42 & $\mathrm{~S}_{3}$ \\
\hline 6 & 10 & 2 & 40 & 42 & $\mathrm{~S}_{4}$ \\
\hline 8 & 8 & 2 & 40 & 42 & $\mathrm{~S}_{5}$ \\
\hline 10 & 6 & 2 & 40 & 42 & $\mathrm{~S}_{6}$ \\
\hline
\end{tabular}

EPR signals of powder glass sample were recorded in Xband at room temperature by using a Bruker EMX spectrometer (Germany), microwave frequency $=9.775 \mathrm{GHz}$, time constant $=81.92 \mathrm{~ms}$ and sweep time $=20.97 \mathrm{~s}$.

\section{Result and Discussion}

\subsection{Spectrum of EPR}

$\mathrm{H}=\beta\left(\mathrm{g}_{/ /} \mathrm{H}_{\mathrm{z}} \mathrm{s}_{\mathrm{z}}\right)+\beta \mathrm{g}_{\perp}\left(\mathrm{H}_{\mathrm{x}} \mathrm{s}_{\mathrm{x}}+\mathrm{H}_{\mathrm{y}} \mathrm{s}_{\mathrm{y}}\right)+\mathrm{A}_{/ / \mathrm{s}_{\mathrm{z}}} \mathrm{I}_{\mathrm{z}}+\mathrm{A} \perp\left(\mathrm{s}_{\mathrm{x}} \mathrm{I}_{\mathrm{x}}+\mathrm{s}_{\mathrm{y}} \mathrm{I}_{\mathrm{y}}\right)$

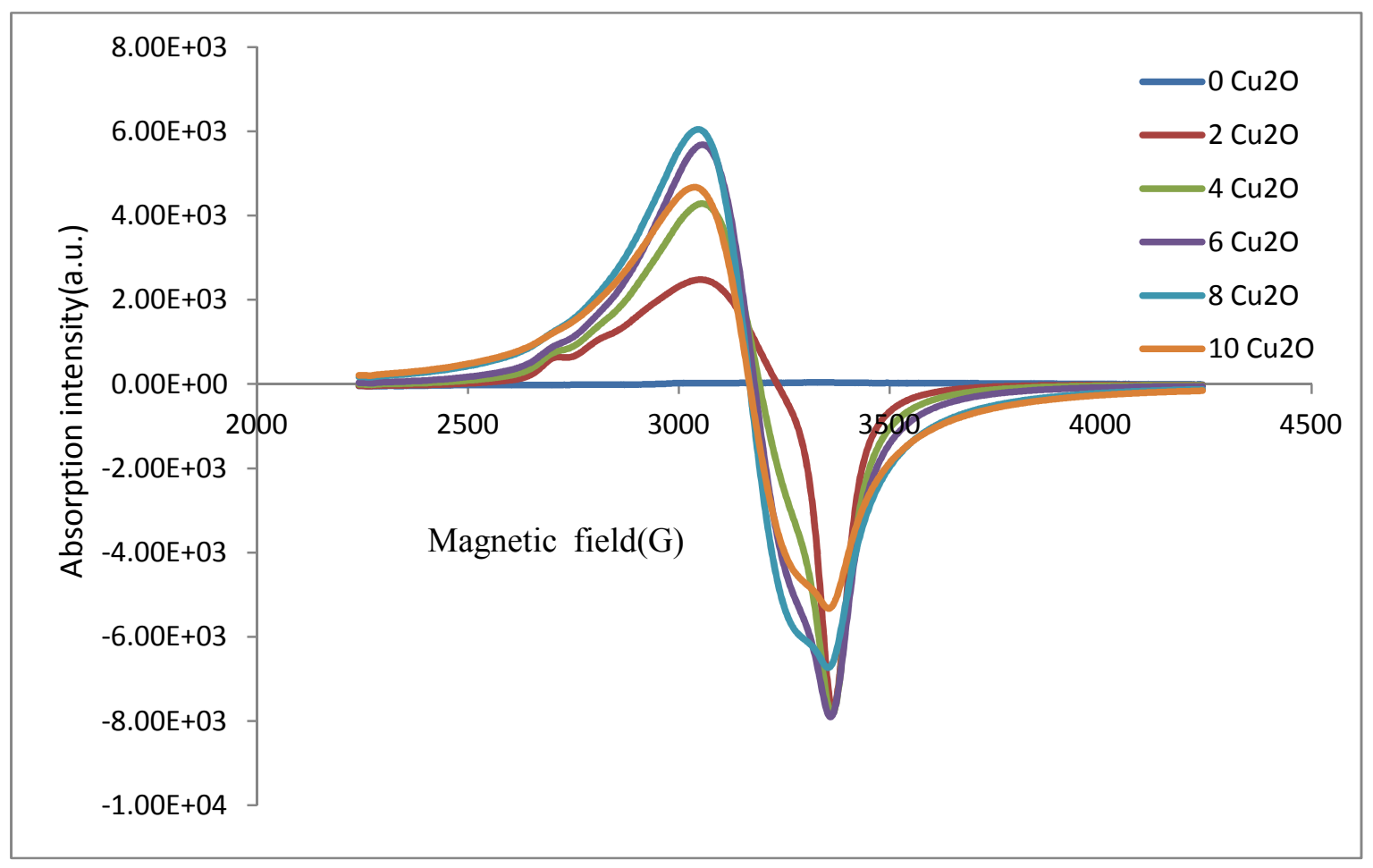

Fig. (1). EPR spectra for obtained system.

Where $\beta$ is the Bohar magnetrons, $\mathrm{g}_{\|}$and $\mathrm{g}_{\perp}$ are parallel and perpendicular principle components of the $\mathrm{g}$ tensor (spectroscopic splitting factor). $\mathrm{A}_{\|}$and $\mathrm{A}_{\perp}$ are the parallel and perpendicular principle components of the hyperfine coupling tensor respectively, $\mathrm{H}_{\mathrm{x}}, \mathrm{H}_{\mathrm{y}}$ and $\mathrm{H}_{\mathrm{z}}$ are components of the magnetic field, $s_{x}, s_{y}, s_{z}$ and $I_{x}, I_{y}, I_{z}$ are the spin operators component of the electron and nucleus respectively.

Generally, octahedral coordination appears as basic coordination of T.M. ions in alkaline or alkaline-earth phosphate glasses $[3,17$, and 18]. In such systems the copper can exhibit three valence states $\mathrm{Cu}^{0}, \mathrm{Cu}^{+1}, \mathrm{Cu}^{+2}$. It is assumed
EPR spectra were recorded at R.T for copper doped $\mathrm{PZnCaNa}$ glass samples in order to examine the valance state of copper in glass matrix fig.(1). Copper free sample exhibits no EPR signal, i.e., all the obtained EPR spectra are due to $\mathrm{Cu}^{+2}$. Each spectrum was analyzed using the axial spin Hamiltonian [19-22]: 
Such an energetically assumption considers a tetragonal elongated octahedron $\mathrm{D}_{4 \mathrm{~h}}$ for the coordination of $\mathrm{Cu}^{2+}$ ion. For $\mathrm{D}_{4 \mathrm{~h}}$ configuration the values obtained for $\mathrm{g}_{\|}$is $<2.4$ and for $\mathrm{A}_{\|}<120 \times 10^{-4} \mathrm{~cm}^{-1}$. In the present work the estimated values for $g_{\perp}>g_{\mid}$and for $A_{\mid}>120 \times 10^{-4} \mathrm{~cm}^{-1}$. To explain the large values obtained for $\mathrm{A}_{\mid}$we suggest that $\mathrm{Cu}^{+2}$ is acted upon by compressed tetrahedral field $\mathrm{T}_{\mathrm{d}}$ and not octahedral tetragonal elongation coordination as it is usually assumed [3, 23-25]. As a result to this structure it is assumed that there is admixing of $3 \mathrm{P}$ states with $4 \mathrm{~d}_{\mathrm{xy}}$ states $[3,26]$.

Inspection of fig. (1) reveals that there is no EPR signal was observed for copper free sample, indicating the absence of paramagnetic center in the prepared glasses and the obtained absorption bands are asymmetric. However, no well-defined trend was observed for different copper concentration. This can be accounted for by the fact that the number of $\mathrm{Cu}^{+2}$ does not increase by increasing copper content. The hyperfine parameters $\mathrm{g}_{\|}, \mathrm{g}_{\perp}, \mathrm{A}_{\|}$and $\mathrm{A}_{\perp}$ are given in Table 2. Inspection these obtained values reveals that $g_{\perp}>$ $\mathrm{g}_{\|}$and $\mathrm{A}_{\|}>\mathrm{A}_{\perp}$, the values allows to assume that $\mathrm{Cu}^{+2}$ is a compressed tetrahedral coordinated configuration since $\mathrm{g}_{\perp}>\mathrm{g}$
" $[3,25]$.In such a case one should expect admixing of 4P states with $3 \mathrm{~d}_{\mathrm{xy}}$ ground states due to compression leading to increase of $g_{\perp}$ and $A_{\|}[3,25]$.

The change in spin Hamiltonian parameters is related to the changes in the ligand field around the T.M. probe ion. It is assumed that EPR spectra consists of overlapping of two bands symmetric and asymmetric band due to cluster and isolated ions, respectively [27, 28]. A symmetric band has a $g$ ${ }_{\perp} \sim 2.27$ and $\mathrm{g}_{\|} \sim 2.09$, but the asymmetric band has average value of $\mathrm{g}_{0} \sim 2.21[27,28]$. Increasing the line width of the parallel spectra $\left(\Delta \beta_{\|}\right)$and the perpendicular spectra $\left(\Delta \beta_{\perp}\right)$ indicates formation of cluster and vice versa.

As shown in fig. (2) $\Delta \beta_{\|}$increases with increasing copper content which means formation of clusters, i.e., $\mathrm{Cu}^{+2}-\mathrm{Cu}^{+2}$ dipole-dipole interaction. While $\Delta \beta_{\perp}$ decrease with copper content until $\mathrm{x}=6 \%$ due to decrease in isolated ions. After $x=6 \%$, there is an increase in clustered ions. The presence of copper as a cluster in the phosphate glass system refers to network modifier of this oxide [27-28].

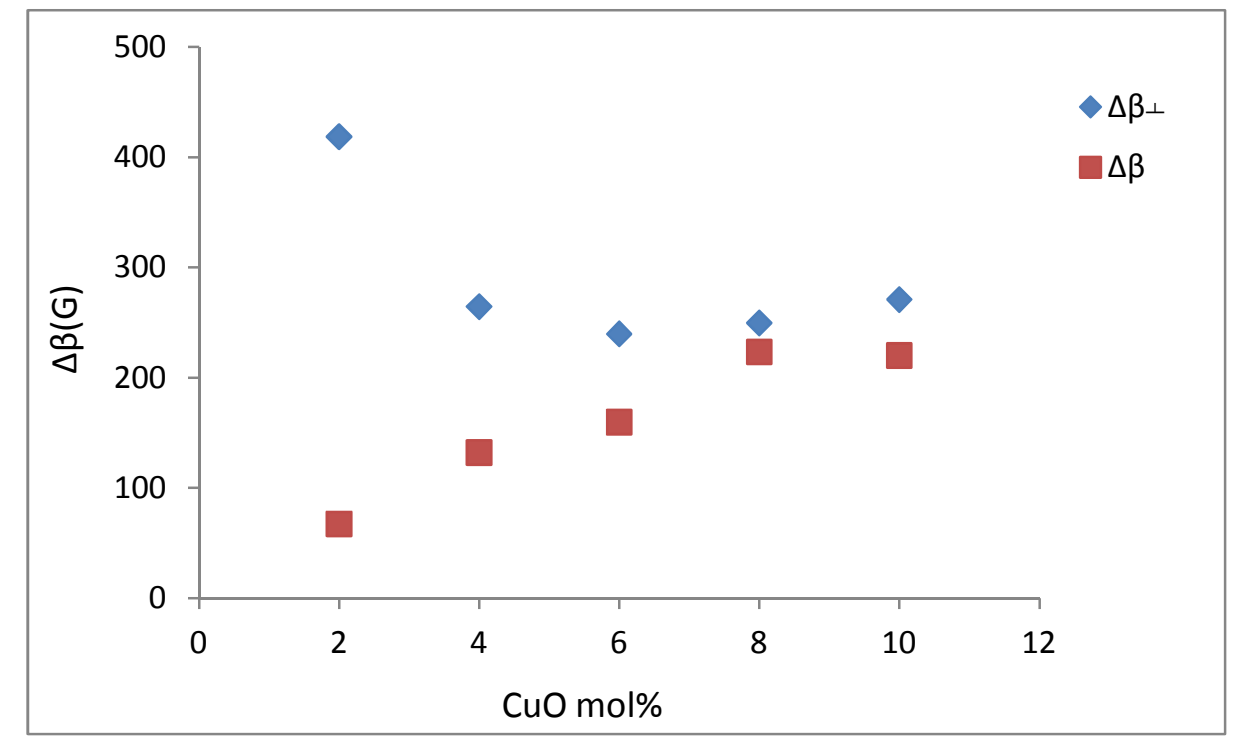

Fig. (2). Variation of perpendicular $\left(\Delta \beta_{\perp}\right)$ and parallel band $\left(\Delta \beta_{I I)}\right.$ width $v$ s copper content.

Table 2. Represent the spin Hamiltonian parameters.

\begin{tabular}{|c|c|c|c|c|c|c|c|c|c|}
\hline No. & No. of spin & $\mathbf{K}$ & $\mathbf{g}_{/ /}$ & $\mathbf{g}_{\perp}$ & $\mathbf{g}_{0}$ & $\Delta \mathbf{g}_{0}$ & $\mathrm{~A}_{/ / /} \mathbf{x} 10^{-4} \mathrm{~cm}^{-1}$ & $A_{\perp} \times 10^{-4} \mathrm{~cm}^{-1}$ & $A_{0} \times 10^{-4} \mathrm{~cm}^{-1}$ \\
\hline S1 & 0 & 0 & 0 & 0 & 0 & 0 & 0 & 0 & 0 \\
\hline $\mathrm{S} 2$ & $7.66 \mathrm{E}+21$ & 1.399 & 2.092 & 2.2696 & 2.21 & 0.21 & 593.01 & 346.82 & 429 \\
\hline S3 & $9.04 \mathrm{E}+21$ & 1.345 & 2.148 & 2.2698 & 2.23 & 0.23 & 508.74 & 349.76 & 403 \\
\hline S4 & $8.65 E+21$ & 1.312 & 2.171 & 2.2668 & 2.23 & 0.235 & 472.17 & 356.12 & 389 \\
\hline S5 & $7.85 E+21$ & 1.30 & 2.184 & 2.275 & 2.24 & 0.245 & 445.16 & 351.35 & 383 \\
\hline S6 & $7.26 \mathrm{E}+21$ & 1.269 & 2.188 & 2.283 & 2.25 & 0.25 & 443.58 & 329.09 & 367 \\
\hline
\end{tabular}

From the spin Hamiltonian parameters, the dipolar term (P) and the Fermi-contact term $(\kappa)$ are calculated using the expressions [29-31]:

$$
\begin{gathered}
\mathrm{P}=2 \gamma_{\mathrm{Cu}} \beta_{0} \beta_{\mathrm{N}}\left(\mathrm{r}^{-3}\right)=0.036 \mathrm{~cm}^{-1} \\
\kappa=\left(A_{0} / P\right)+\Delta g_{0}
\end{gathered}
$$

Where $\gamma_{\mathrm{Cu}}$ is the magnetic moment of copper, $\beta_{0}$ is the
Boharmagneton, $\beta_{\mathrm{N}}$ is nuclear magnet on and $\mathrm{r}$ is the distance from the central nucleus to the electron. The Fermi-contact term $\kappa$ is a measure of the polarization produced by odd distribution of d-electron density on the inner core s-electron, $\mathrm{A}_{0}=\left(\mathrm{A}_{\|}+2 \mathrm{~A}_{\perp}\right) / 3, \mathrm{~g}_{0}=\left(\mathrm{g}_{\|}+2 \mathrm{~g}_{\perp}\right) / 3, \Delta \mathrm{g}_{0}=\mathrm{g}_{\mathrm{o}}-\mathrm{g}_{\mathrm{e}}$. The calculated data of $\kappa$ are listed in table 2 . From (table 2), it is found that there is general decrease in these values, i.e., decrease in the polarizabilities[29-32]. 


\subsection{Paramagnetic Susceptibility}

The EPR data can be used to calculate the paramagnetic susceptibility of the sample using the formula [33, 34]:

$$
\chi=\frac{N g^{2} \beta^{2} j(j+1)}{3 k_{B} T}
$$

Where $\mathrm{N}$ is the number of spins per $\mathrm{cm}^{3}$, the rest of the symbols have their usual meaning. The paramagnetic susceptibility was calculated at different concentration. Figure (3) shows a plot of paramagnetic susceptibility $(\chi)$ of $\mathrm{Cu}^{2+}$ ions glass system as a function of concentration.

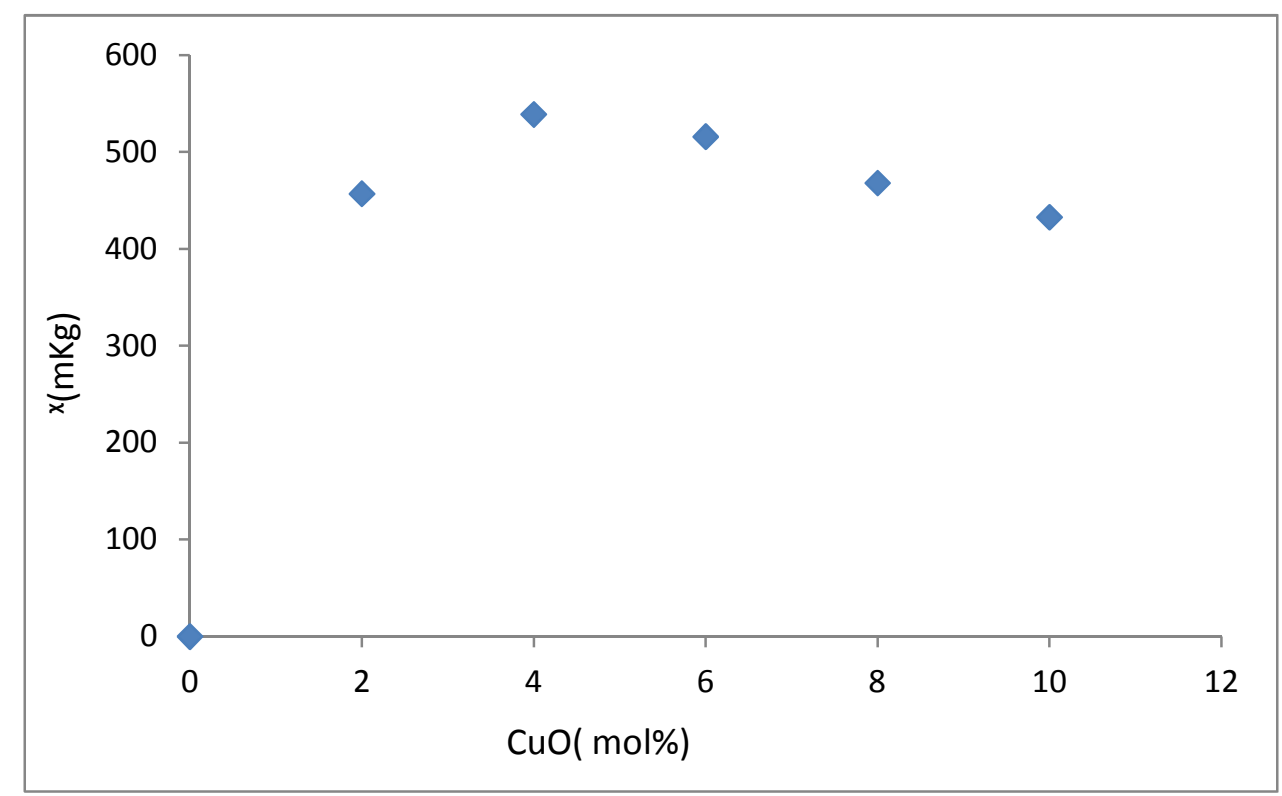

Fig. (3). paramagnetic susceptibility ( $\chi$ ) with $\mathrm{Cu}_{2} \mathrm{O}$ content.

The figure shows that magnetic susceptibility depends on copper glass-oxide content. So, the change in magnetic susceptibility is due to percentage of $\mathrm{Cu}^{+2}$ formation only because the $\mathrm{Cu}^{+1}$ ions have zero magnetic moment [16]. So, the increase in the magnetic susceptibility by increasing the copper content up to $4 \%$ due to increase in $\mathrm{Cu}^{+2}$. Then, by increasing the copper content over $4 \%$, there is decrease in the magnetic susceptibility due to change $\mathrm{Cu}^{+1}$ to $\mathrm{Cu}^{+2}$, i.e., ratioCu ${ }^{+1} / \mathrm{Cu}^{+2}$ increases.

\subsection{Optical Basicity $\left(\wedge_{t h}\right)$}

On the other hand, the change in the EPR with copper content can be most likely related the change in electron cloud density of oxygen at the $\mathrm{Cu}^{2+}$ ions in the glass network. The optical basicity $\left(\wedge_{\mathrm{th}}\right)$ is a measure of electron donor power of oxygen anion around cation (T.M.), i.e., the degree of covalency of bonds between $\mathrm{O}^{2-}$ and polarizing ion. The optical basicity $\left(\wedge_{\text {th }}\right)$ for the glass system under study has been calculated using the relation [35]:

$$
\begin{aligned}
& \wedge_{\mathrm{th}}= \mathrm{x}_{1}\left(\mathrm{P}_{2} \mathrm{O}_{5}\right) \wedge\left(\mathrm{P}_{2} \mathrm{O}_{5}\right)+\mathrm{x}_{2}(\mathrm{ZnO}) \wedge(\mathrm{ZnO})+\mathrm{x}_{3}\left(\mathrm{Na}_{2} \mathrm{O}\right) \wedge \\
&\left.\left(\mathrm{Na}_{2} \mathrm{O}\right)+\mathrm{x}_{4}(\mathrm{CuO}) \wedge(\mathrm{CuO})+\mathrm{xCaO}\right) \wedge(\mathrm{CaO})
\end{aligned}
$$

Where x's are the equivalent fractions of the different oxides, i.e., the proportion of the oxide that they contribute to the glass system and $\wedge\left(\mathrm{Na}_{2} \mathrm{O}\right), \wedge(\mathrm{ZnO}), \wedge\left(\mathrm{P}_{2} \mathrm{O}_{5}\right), \wedge(\mathrm{CaO})$ and $\wedge(\mathrm{CuO})$ are optical basicity values assigned to the constituent oxides. Here the values of $\wedge\left(\mathrm{Na}_{2} \mathrm{O}\right)=1.15, \wedge$ $(\mathrm{ZnO})=0.82, \wedge\left(\mathrm{P}_{2} \mathrm{O}_{5}\right)=0.4, \wedge(\mathrm{CaO})=1$ and $\wedge\left(\mathrm{Cu}_{2} \mathrm{O}\right)=$ 0.97 have been taken from literature. The calculated values of $\Lambda_{\text {th }}$ are presented in Table3. It is found that the optical basicity for the present system lies between 0.696 and 0.681 , i.e., decreases with increasing $\mathrm{Cu}_{2} \mathrm{O}$ content. According to this calculation, it can be concluded that $\mathrm{Cu}^{2+}$ ions are surrounded by mostly bridging oxygen which may increase electron cloud density at the $\mathrm{Cu}^{2+}$ site, i.e., decrease in the polarizability and hence the changes in spin-Hamiltonian parameters as observed[36, 37].Also the change in EPR parameters depends on differences in the field intensities and the cationpolarizabilities $\mathrm{P}^{+5}, \mathrm{Ca}^{+2}, \mathrm{Zn}^{+2}, \mathrm{Na}^{+1}$ which make fluctuations in the ligand field around $\mathrm{Cu}^{+2}$ ions[38]. This is consistent with $\kappa$ values which indicates the decrease of polarizability[36, 37].

Table 3. represent the magnetic susceptibility and the optical basicity.

\begin{tabular}{lll}
\hline No. & $\chi$ & $\wedge_{\text {th }}$ \\
\hline S2 & 456.95 & 0.696 \\
S3 & 538.87 & 0.6928 \\
S4 & 515.85 & 0.6892 \\
S5 & 468.032 & 0.6856 \\
S6 & 432.73 & 0.681 \\
\hline
\end{tabular}




\section{Conclusion}

1- It is found that $\mathrm{g}_{\perp}>\mathrm{g}_{\|}$which mean that $\mathrm{Cu}^{+2}$ are present in tetrahedral coordination as well as octahedral distortion and ground state is $\mathrm{d}_{\mathrm{xy}}$.

2-Paramagnetic susceptibility $(\chi)$ depends on $\mathrm{Cu}^{+}$ concentrations.

3-Calculation optical basicity indicates that there is decrease in the polarizability with increasing copper content which is supported by results of Fermi-contact term $(\kappa)$.

\section{References}

[1] S. Y. Marzouk, Mater. Chem. Phys. 114 (2009) 188-193.

[2] M. J. Weber, J. D. Meyers, D. H. Blackburn, J. Appl. Phys. 52 (1981) 2944-949.

[3] N. Vedeanu ${ }^{a}$, D. A. Magdas ${ }^{\text {b, }}$, R. Stefan ${ }^{\text {c }}$, Journal of NonCrystalline Solids 358(2012)3170-3174.

[4] E. M. Vogel, M. J. Waber, D. M. Krol, Phys. Chem. Glasses 32 (1991) 231-254.

[5] El-Mallawany, Tellurite Glasses Handbook: Physical Properties and Data, CRC

[6] Y. M. Moustafa, A. El-Adawy, Phys. Status Solidi A 179 (2000) 83-93.

[7] M. H. Asghar, M. Shoaib, F. Placido, S. Naseem, Curr. Appl. Phys. 9 (2009) 1046-1053.

[8] F. H. El-Batal, J. Mater. Sci. 43 (2008) 1070-1107.

[9] B. S. Boe, M. C. Weinberg, J. Am. Ceram. Soc. 74(1991)39.

[10] M. A. Salim, G. D. Khattak, M. S. Hussain, J. Non-Cryst. Solids185 (1995)101.

[11] H. Zheng, M. W. Colby, J. D. Mackenzie, J. Non-Cryst. Solids127 (1991)143.

[12] A. Mekki, D. Holland, K. Zig, C. F. McConvieke, Phys. Chem. Glasses39 (1998)183.

[13] EzzEldin Metwalli, J. Non-Cryst. Solids317 (2003)221.

[14] G. Lakshminarayana, S. Buddhudu, Spectrochim. Acta Part A62 (2005)364.

[15] G. D. Khattak, A. Mekki, L. E. Wenger, J. Non-Cryst. Solids337(2004)174.

[16] S. SreehariSastry ${ }^{\mathrm{a}, ~}{ }^{*}$, B. Rupa Venkateswara Rao ${ }^{\mathrm{a}, \mathrm{b}}$, PhysicaB 434(2014)159-164

[17] L. D. Bogomolova, A. G. Fedorov, V. A. Jachkin, V. N.
Lazukin, T. K. Pavlushkina, J. Non-Cryst. Solids 44 (1981) 191-194.

[18] A. Abragam, M. H. L. Pryce, Proc. R. Soc. Lond. A 205(1951)135-153.

[19] P. Y. Shih, J. D. Ding, S. Y. Lee, Mater. Chem. Phys. 80 (2003) 391-396.

[20] P. Nageswara Rao, B. V. Raghavaiah, D. Krishna Rao, N. Veeraiah, Mater. Chem. Phys. 91(2005)381-390.

[21] B. B. Das, Deepa, J. Non-Cryst. Solids 355 (2009) 1663-1665.

[22] G. Upender, M. Prasad, V. Chandra Mouli, J. Non-Cryst. Solids 357 (2011)903-909.

[23] K. V. Ramesh, D. L. Sastry, J. Non-Cryst. Solids 352 (2006) $5421-5428$

[24] C. Mercier, G. Palavit, L. Montagne, C. Follet-Houttemane, C. R. Chimie 5 (2002) 693-703.

[25] D. A. Magdas, O. Cozar, V. Chis, I. Ardelean, N. Vedeanu, Vib. Spectrosc. 482 (2008) 251-254.

[26] C. A. Bates, W. S. Moore, K. J. Standley, K. W. H. Stevens, Proc. Phys. Soc. 79 (1962) 73-83.

[27] Cozar, 0. And Ardelean, I. , J. Non-Cryst. Solids, 92(1987) 278.

[28] Ardelean, I., Peteanu, M. , Burzo, E. , Filip, S. and Ciorcas, F. , Solid State commun. , 98, (1996)351.

[29] G. Giridhar ${ }^{1)}$, M. Rangacharyulu ${ }^{1)}$, R. V.S. S. N. Ravikumar ${ }^{1)}$ and P. Sambasiva Rao ${ }^{2}$, J. Mater. Sci. Technol. , Vol. 25 No. 4, (2009) 531.

[30] D. Kivelson and R. Neiman: J. Chem. Phys. , 35(1961)149.

[31] K. E. Falk, E. Ivaniva, B. Roos and T. Vanngard: In-org. Chem., 9 (1970) 556.

[32] J. H. VanVleck: Phys. Rev., 41(1932) 208.

[33] N. W. Aschcroft, N. D. Mermin, Solid State Physics, Harcourt College Publisher, New York, (2001) 656.

[34] K. Srinivasulu a I. Omkaram ${ }^{\text {b }, ~ H . ~ O b e i d ~}{ }^{c}$, A. Suresh Kumar ${ }^{a}$, J.

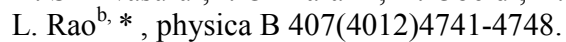

[35] J. A. Duffy, M. D. Ingram, in: D. Uhlman, N. Kreidl (Eds. ), Optical Properties of Glasses, American Ceramic Society, Westerville, 1991.

[36] V. Dimitrov, S. Sakka, J. Appl. Phys. 79 (1996) 1736-1740.

[37] V. Dimitrov, T. Komatsu, J. Univ. Chem. Technol. Metall. 45 (2010) 219-250. 